Portland State University

PDXScholar

$5-19-1988$

\title{
Effects of Feedback and Goal Setting on Job Attitudes and Productivity: A Field Study
}

Stephen Kildahl

Portland State University

Follow this and additional works at: https://pdxscholar.library.pdx.edu/open_access_etds

Part of the Psychology Commons

Let us know how access to this document benefits you.

\section{Recommended Citation}

Kildahl, Stephen, "Effects of Feedback and Goal Setting on Job Attitudes and Productivity: A Field Study" (1988). Dissertations and Theses. Paper 3813.

https://doi.org/10.15760/etd.5697

This Thesis is brought to you for free and open access. It has been accepted for inclusion in Dissertations and Theses by an authorized administrator of PDXScholar. Please contact us if we can make this document more accessible: pdxscholar@pdx.edu. 
AN ABSTRACT OF THE THESIS OF stephen Kildahl for the Master of Science in Psychology presented May 19, 1988.

Title: Effects of Feedback and Goal Setting on Job Attitudes and Productivity: A Field study.

APPROVED BY MEMBERS OF THE THESIS COMMITTEE:

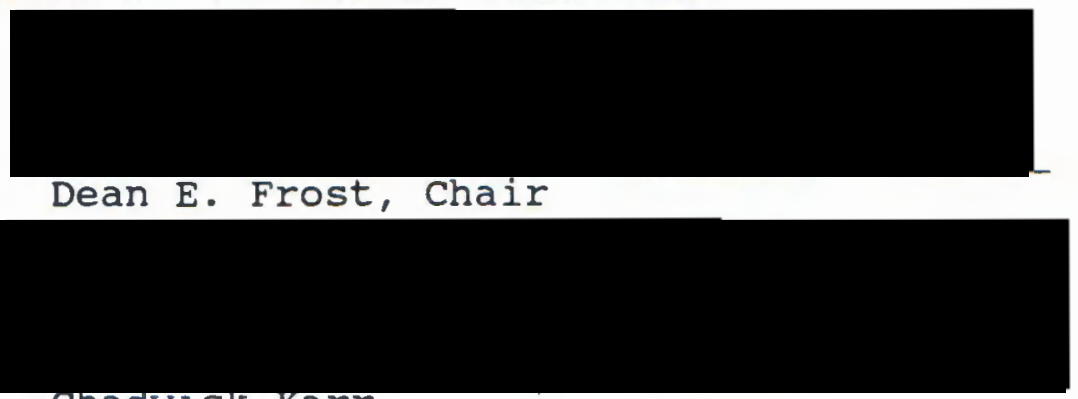

Chadw1ck Karr

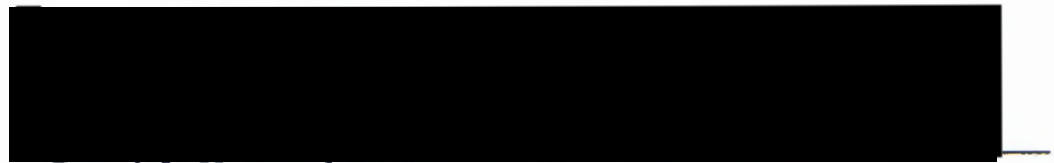

David wrench

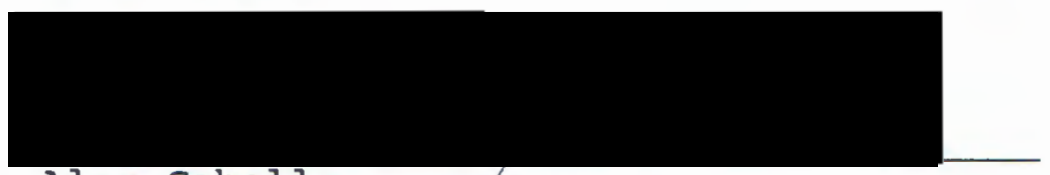

Alan Cabelly

Two theories of work motivation taken from the

field of Industrial/organizational Psychology were

compared in a six-week field experiment at a Fortune 500

company. A Job Enrichment Model (Hackman \& Oldham, 1975)

was used and the Motivating Potential Score (MPS) of

three groups of machine operators was obtained before and after a six-week productivity study. Three goal 
conditions based on Goal Theory (Locke, 1968) were assigned one to each of three groups of machine operators and comparisons were made between the treatment groups. Production increases resulted from providing goals and feedback to subjects, but these increases were not statistically significant. The hourly goal condition with feedback had the largest increase over baseline, greater than either daily goals with feedback or the "do your best" goal condition with no feedback. A weak correlation exists $(\underline{r}=.17)$ between the change in worker's MPS and the worker's change in production. 
EFFECTS OF FEEDBACK AND GOAL SETTING ON JOB ATTITUDES AND PRODUCTIVITY: A FIELD STUDY

\title{
by
}

STEPHEN KILDAHL

A thesis submitted in partial fulfillment of the requirements for the degree of

\author{
MASTER OF SCIENCE \\ in \\ PSYCHOLOGY
}

Portland State University

1988 
TO THE OFFICE OF GRADUATE STUDIES:

The members of the committee approve the thesis of Stephen Kildahl presented May 19, 1988.

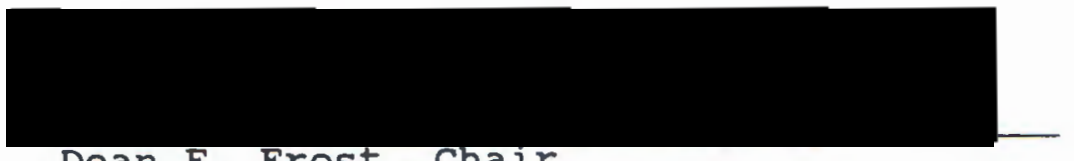

Dean E. Frost, Chair

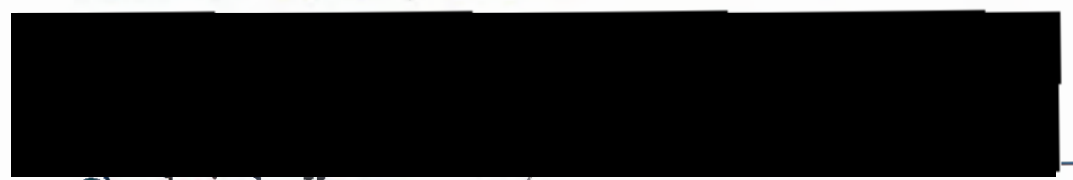

Chadwick Karr

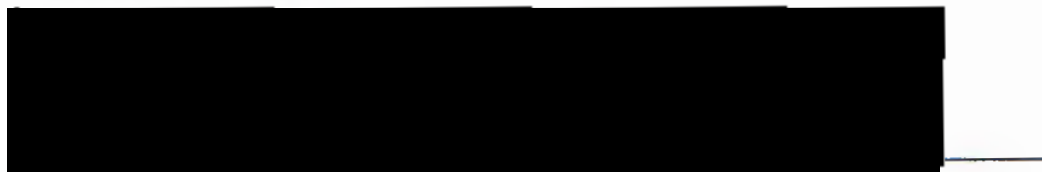

David wrench

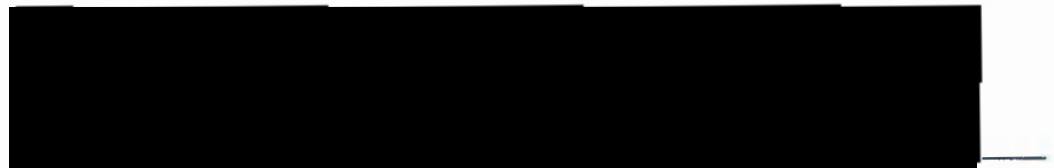

Alan Cabelly

APPROVED :

Rogef D. Jennings, Head, Department of Psychology

Bernard Ross, Vice Provost for Graduate studies 
ACKNOWLEDGEMENTS

I wish to express my appreciation to OMARK Industries and Bill Simpson, V.P. for their cooperative and patient assistance. Without Mr. Simpson, this study would not have been possible.

Special acknowledgement is due to Pete Barnett, Personnel Manager, and the supervisors, Jim Norris, Pete Scott, and Mike Skiles, for implementing this study unselfishly into the work place.

I wish to acknowledge my committee. Dean Frost, Chair and Advisor, contributed his talents and expertise all hours of the day. Thank you. David Wrench, Graduate Advisor, has been supportive of my efforts all through my graduate studies. Thank you. Alan Cabelly, Graduate Representative, added his knowledge of the subject expertly and humanely. Thank you.

Chad Karr, Professor and friend, like the excellent educator he is, gave of himself and enriched this student beyond my ability to thank.

To my friends, those people who supported me often when I faltered and encouraged me convincingly when I weakened, thank you. 
No man's friend could do more for his fellow than John Skiles, M.S.. Spence Meighan, M.D., has exquisite timing and is a credit to his profession. Zeno Idzerda and David Kildahl will forget more mathematics than I will ever know and their statistical assistance is here acknowledged. Thank you.

No thesis can be completed without the clerical skills of Linda Kuhlmann, a God-send who worked with competence and efficiency. Thank you.

I wish to acknowledge my wife, Marilyn Gendason, whose emotional support and depth is outdone only by my love for her.

Concluding with those people most deserving, I wish to express my appreciation and life-long love for Phillip Kildahl, P.H.D. and Helen Kildahl, my father and mother, to whom this work is dedicated. 
TABLE OF CONTENTS

PAGE

ACKNOWLEDGEMENTS • . • . . . . . . . . . . . .

LIST OF TABLES . . . . . . . . . . . . . vii

LIST OF FIGURES . . . . . . . . . . . . . . . . viii

CHAPTER

I INTRODUCTION . . . . . . . . . . . . . 1

Job Characteristics Model . . . . . . 2

The Five Core Job Dimensions

The Three Critical Psychological states

The Motivating Potential Score

Goal Theory . . . . . . . . . . .

Goal Difficulty and clarity

Goals and Feedback

Goals and Need to Achieve

Hypothesis . . . . . . . . . . . 13

II METHOD . . . . . . . . . . . . . 16

Subjects

Machines

Shifts

Survey Instrument

Procedure

Control Condition

Experimental Conditions

Feedback -- Hourly Goal Condition

Feedback -- Daily Goal Condition

III RESULTS . . . . . . . . . . . . . . 24

IV DISCUSSION . . . . . . . . . . . . 29 
PAGE

APPENDIX A . . . . . . . . . . . . . . . . . . 40

APPENDIX B . . . . . . . . . . . . . . . 42

APPENDIX C . . . . . . . . . . . . . . . . . . . 43

APPENDIX D . . . . . . . . . . . . . . . . . 44

APPENDIX E . . . . . . . . . . . . . . . . . 45 


\section{LIST OF TABLES}

TABLE

PAGE

I The Difference In Run-Time Means Before and After Treatment, and the standard Deviation by condition . . . . . . . . . . . . 24

II A One Way Analysis of Variance Using Change Scores on Run-Time . . . . . . . . . . 26

II Change in Motivating Potential score and Change in Production by Subject . . . . 27

IV Motivating Potential score Change from Pre to Post Testing . . . . . . . . . . . 28 


\section{LIST OF FIGURES}

FIGURE

PAGE

1. Diagram of the Job Characteristics Model . . 5

2. Diagram of the Three Conditions and

Chronological Sequence of Events . . . . . . 21 


\section{CHAPTER I}

\section{INTRODUCTION}

This thesis reports the results of research carried out at OMARK Industries' chain assembly plant located in Portland, Oregon, in the summer of 1986. Two theories from Industrial/organizational Psychology were compared in this field experiment: Job Characteristics Model (Hackman \& Oldham, 1975) and Goal Theory (Locke, 1968) .

Following a description of Job Characteristics Model and Goal Theory is a discussion of the literature supporting these two theories together with information on knowledge of results or feedback. The methods section describes the subjects in the study, the machines they operated, information concerning the work place, and the self-report instrument used to assess the worker's perception of his job. The procedure section describes the three experimental test conditions for the subjects: (a) hourly goals with feedback, (b) daily goals with feedback, and (c) a "do your best" goal with no feedback. The results section reports the findings of the statistical tests. The discussion section provides an explanation of the results, discusses the constraints of 
the work place, problems encountered in the study, and the benefits derived from this research.

\section{JOB CHARACTERISTICS MODEL}

Job Characteristics Model (Hackman \& Oldham, 1975) holds that a job has certain characteristics that can be measured and altered to increase internal work motivation of the worker. Herzberg and others had suggested in an earlier work that worker perceptions of opportunity, achievement, recognition, growth, and challenge contribute to the feelings of job satisfaction which may, in turn, increase productivity (Herzberg, Mauser, \& Snyderman, 1959). The relationship they set forth was not experimentally verified, but it initiated research that helped produce today's better understanding of job characteristics.

Later, Hackman and Lawler (1971) adapted four "core" job dimensions from the Requisite Task Attributes previously developed by Turner and Lawrence (1965). To those four job dimensions--skill Variety, Task Identity, Autonomy, and Feedback--Hackman and oldham (1975) added Task Significance to create the "Job Characteristic Model." These five scales combine to produce a Motivating Potential Score, one of the dependent variables used in this study. 
According to this model then, there are five core job dimensions. Each dimension is a situational variable hypothesized to affect one of three critical psychological states which in turn combine to affect personal and work outcomes. These job dimensions, psychological states, and personal and work outcomes and their relationships are presented in Figure 1.

\section{The Five Core Job Dimensions}

The first job dimension, Task Identity, is defined as: "The degree to which a job requires a variety of different activities in carrying out the work, involving the use of a number of different skills and talents for the person" (Hackman \& Oldham, 1980). The second dimension, Task Identity, is defined as: "The degree to which a job requires completion of a whole and identifiable piece of work...doing a job from beginning to end with a visible outcome" (Hackman \& Oldham, 1980). The third dimension, Task Significance, is defined as: "The degree to which the job has a substantial impact on the lives of other people, whether those people are in the immediate organization or in the world at large" (Hackman \& Oldham, 1980). As shown in Figure 1, the combined influence of the first three job dimensions is hypothesized to create the meaningfulness of the job as perceived by the worker. 
The fourth job dimension is Autonomy and is defined as: "The degree to which the job provides substantial freedom, independence, and discretion to the individual in scheduling the work and in determining the procedures to be used in carrying it out" (Hackman \& Oldham, 1980). The worker has control over his own work, and that control is hypothesized to generate a feeling of responsibility for the outcomes of the work (see Figure 1).

The fifth job dimensions is Feedback. Feedback can be generated from the work environment itself or from a person with the requisite information, such as a supervisor. Organizational psychologists believe that feedback gained by the worker directly from the work place itself is more effective than verbal feedback gained from someone else. It follows that feedback gained from one's own observation of one's own work would be immediate, whereas feedback provided by another person would tend to be delayed. Also, self-feedback is not subject to interpretation by the worker looking for a hidden motive or for a more favorable opinion (Pinder, 1984). The feedback provided in this study is worker generated and does not rely on the accuracy and fairness of another person. Feedback is hypothesized to be experienced as knowledge of results of work activities (see Figure 1). 


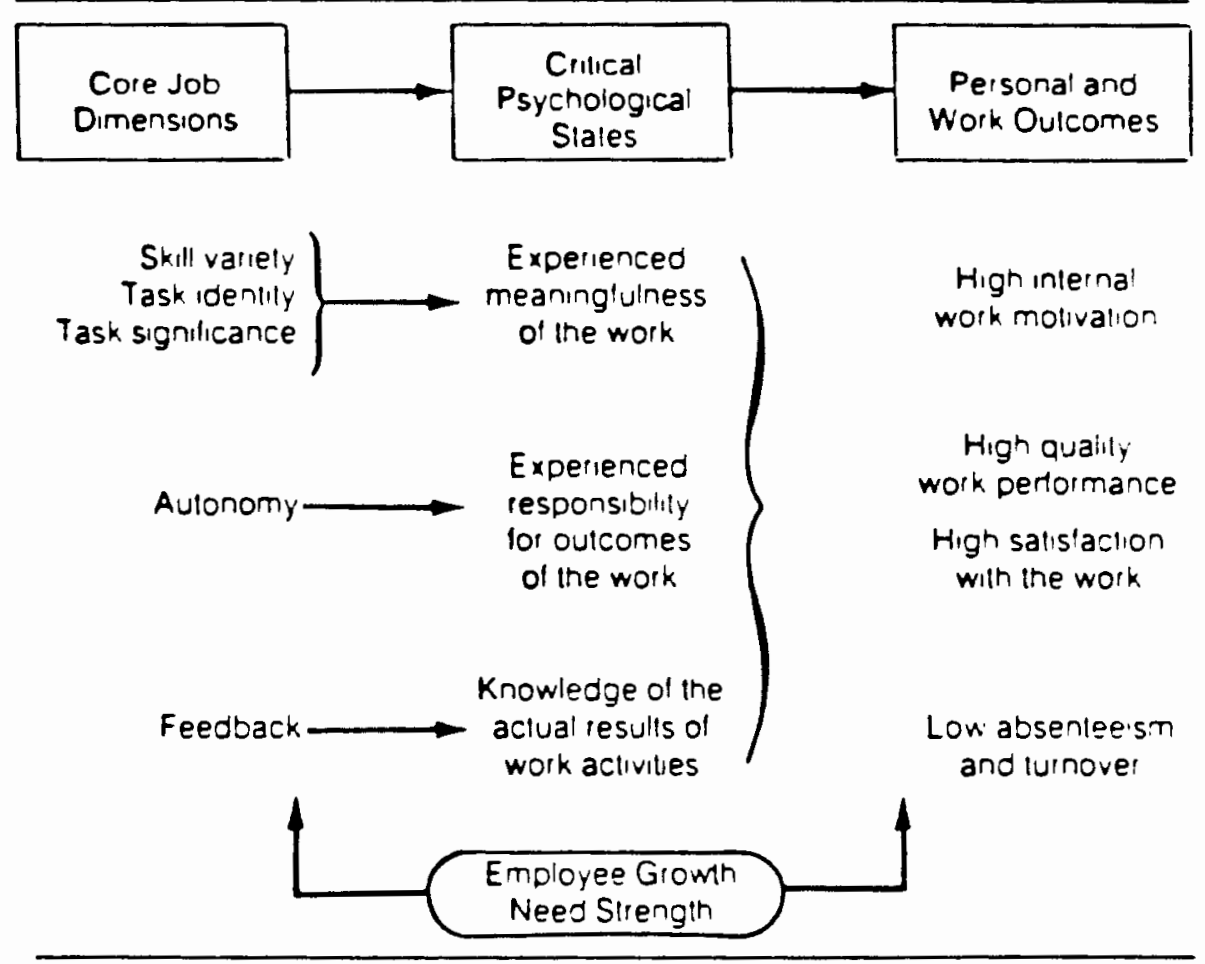

Figure 1. Diagram of the Job Characteristics Model.

The Three critical Psychological states

The first psychological state is Experienced Meaningfulness of the work. According to the Job Characteristics Model, the first three job dimensions defined by Hackman and Oldham (1980)--skill Variety, Task Identity, and Task Significance--are additive and together contribute to the worker's perception of meaningfulness. (See Figure 1)

The second psychological state is Experienced Responsibility for the outcomes of the work. This feeling of responsibility is the hypothesized result of providing autonomy to the worker as defined above. 
The third psychological state is Knowledge of the Actual Results of Work Activities. This hypothesized cognitive variable is assumed to occur when feedback to the worker of the worker's efforts is provided.

\section{The Motivating Potential Score}

Hackman and Oldham (1975) have devised the Job Diagnostic Survey, a pencil and paper instrument designed to assess the degree of activation of the three hypothesized Critical Psychological states in the worker. Each worker fills out the survey instrument and a score for each of the five job dimensions is calculated. These five scores are entered into the following formula to obtain the Motivating Potential Score (MPS).

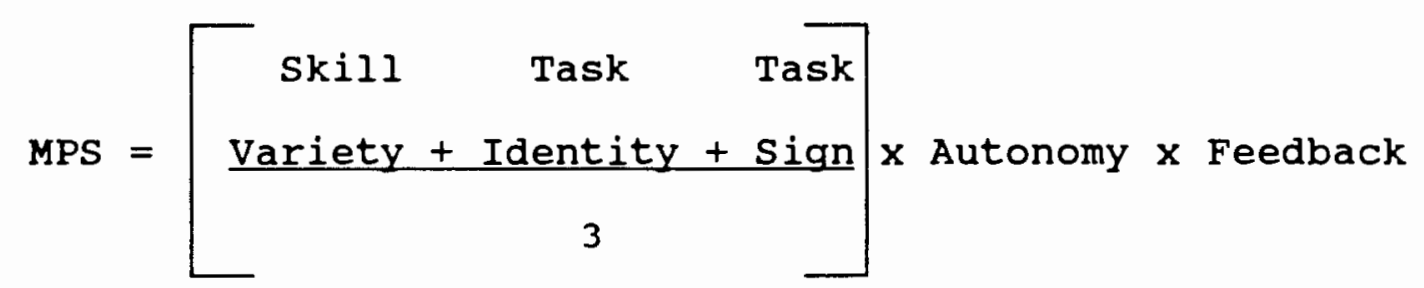

It is easily seen that an improvement in score of any of the five characteristics, as measured by the Job Diagnostic Survey (Hackman \& Oldham, 1975), will increase the MPS, but improvement in autonomy or feedback will have the greatest impact on the total.

Unfortunately, there is no easy way to validate this theory, and research attempting to do so has failed to support the theory. But the Job Characteristics Model has gained the support of academicians despite its lack of 
empirical support (Pinder, 1984). It should be noted that the failure of research to provide support does not mean that the theory is necessarily wrong.

\section{GOAL THEORY}

In contrast, Goal Theory does not take into account hypothetical psychological states as a source of motivation. Just the acceptance of a meaningful, moderately difficult goal, plus knowledge of results or feedback, is sufficient to increase a worker's productivity (Locke, 1968).

The exact nature of how goals work has not been discussed in the literature, but there is evidence that goals direct attention and action. In the study by Locke and Bryan (1969), drivers were given feedback on five different dimensions of driving but were assigned goals on only one dimension. The performance on the driving dimension with an assigned a goal showed significantly more improvement than on the other four dimensions. The presence of goals may also cause competition between subjects to occur. Latham and Baldes (1975) and Komaki and Dare-Boyce (1978) found that goal setting plus feedback led to spontaneous competition among subjects. It is likely that competition could lead to greater goal commitment (Locke, 1968). 
Goal Difficulty and Clarity

The behavioral aspects of goal setting and resulting performance have been discussed in detail by Locke (1968). Locke demonstrated that difficult or hard goals produce higher levels of performance or output than easy goals. Workers rise to the challenge of increased expectations imposed by others. In this oft cited article, Locke also demonstrated that specific goals produce a higher level of output than a "do your best" goal. Locke also reported evidence for a positive, linear relation between goal difficulty and the level of performance of the task.

other studies have reported a positive relationship between goal difficulty and performance (Becker, 1978; Erez, 1979; Strang, Lawrence, \& Fowler, 1978). In these studies the subjects who had high goals assigned to them and who received feedback (knowledge of results) concerning their progress toward the assigned goals performed better than those with low goals and no feedback.

Three related studies showed that difficult goals led to better performance than nonspecific, "do your best" goals (Bassett, 1979; Latham \& Locke, 1975; Yukl \& Latham, 1978). It follows that the more challenging and specific the goal and the more relevant it is perceived, the more effect it will have on performance. Locke 
stated that goal acceptance implies that one has agreed to commit oneself to a goal assigned or suggested by another. Acceptance of a goal by the subject is essential. The unaccepted goal is no more than an assigned task and, by itself, will not contribute to improved performance. Simply setting a goal does not, in itself, improve performance (Locke, 1968).

In another study, goal clarity, or the specifically assigned task and result, correlated with increased effort only for managers who were mature and decisive and who had low job interest and low support from their managers (Carroll \& Tosi, 1970). Perhaps the addition of goals to the managers' tasks enriched their jobs, provided more job satisfaction, and led to increased effort by making the work or goal more relevant.

\section{Goals and Feedback}

The Locke, Shaw, Saari, and Latham (1981) study concluded that both goals and feedback are necessary to improve results. The purpose of feedback is to inform the subject of his or her level of achievement. The goal, to an achievement oriented individual provides focus for his or her own motivation. Together, feedback and goals should help to enhance a person's motivation to contribute an improved performance in the work place and should also contribute to increased job satisfaction of the worker. 
The use of feedback and goal setting as aids to performance is not a new proposal. There is a wealth of data in the psychological literature which supports the benefits of verbal, visual, or mechanical feedback in both clinical and laboratory settings.

Matsui, Okada, and Inoshita (1983) found that goals and feedback improved performance among subjects whose initial performance was below the average of the total experimental group. They further demonstrated that goal setting and feedback affect progress by inducing a larger effort from low ability subjects than from high ability subjects. Although these findings were significant, the experimental setting was artificial and the duration of the experimental condition was ten minutes.

It seems possible that performance levels of subjects producing currently at higher efficiency show less improvement when given tools designed to increase productivity simply because they have less room for improvement. Subjects who perform below the mean on productivity for the total group have the potential of producing the greatest statistical improvement with similar absolute productivity gains. Apparently, submean performers gain more benefit from production enhancing tools in part because these tools facilitate focusing their attention on the task or goal. 
Knowledge of results or feedback has been studied in relation to goal setting to see if it directly influences performance or whether its effects are mediated by the goal setting activity. The Locke (1967), and Locke and Bryan (1968) studies provided all subjects with specific goals and provided feedback to the workers on their performance in relation to their goal. subjects in the Knowledge of Results condition received feedback of their actual scores in a way that precluded its use in setting a goal. Knowledge of results, in itself, did not lead to better scores than the No Goal and No Knowledge of Results conditions. There were no groups, however, that had goals and no feedback. These studies did not test the possibility that knowledge of results may be a necessary condition for goals to affect performance (c.f., Locke, Shaw, Saari, \& Latham, 1981).

A study by Latham and Yukl (1975) involved logging crews which showed improvements in performance in one of three goal setting conditions over a no goal set condition. The lack of improvement within two of the goal conditions was attributed to lack of support by local management. Again, although demonstrating that set goals produce more than no-goal-set conditions, acceptance of goals is essential. The goal must also be perceived as credible. 
Frost and Mahoney (1976) demonstrated the presence of feedback as the difference between successful and unsuccessful attainment of set goals. However, when feedback was eliminated later in the Frost and Mahoney study, those subjects working with moderately difficult goals actually performed less well than those subjects assigned average goals. Subjects with high or moderately high goals who received feedback performed better with the aid of feedback than subjects with average goals.

Feedback has been shown to be a necessary and essential condition for goals to affect performance according to Erez (1977), Becker (1978), and strang et al. (1978). These studies found that only subjects receiving feedback improved their performance toward attaining a goal. A goal must be accepted by the worker in order to be relevant. The goal must be cognitively perceived as real.

\section{Goals and Need To Achieve}

Steers (1975) found that performance was related to feedback and goals only for high need-for-achievement individuals. The need-for-achievement concept was first studied by Mcclelland and refers to the motive to achieve some standard of accomplishment or proficiency (Mcclelland, 1953). These findings indicate that subjects who have a "need to achieve" perform best when 
they receive feedback on specifically assigned goals.

Again, subjects with a strong achievement motive or need for achievement prefer moderately difficult goals or risks. They want concrete feedback regarding task performance, and prefer tasks where skill rather than luck determines the outcome. They seek tasks where they will have personal responsibility and tend to err somewhat on the side of optimism in estimating their chances for success.

Subjects with high need to achieve will seek challenges and will push themselves to improve their performance. If workers with a high need to achieve are provided with information in the form of goals and feedback, they are expected to utilize the information to improve their own performance. Not all people, though, will seek or utilize this information. Not all people, because of individual differences, will increase work output by the introduction of achievement oriented conditions.

\section{HYPOTHESES}

My research project took place in a factory environment. Through normal managerial channels, I had feedback and goals introduced into the work place after I obtained a Motivating Potential score from the workers by administering the Job Diagnostic Survey. I re- 
administered the JDS to measure the workers' perceptions of the job at the conclusion of the experimental period to test two hypotheses.

It is necessary to point out that Locke's theory requires not only the presence of a goal, but that the goal selected be of optimum difficulty. The literature is clear that easy goals, those goals attained with little effort, and unreasonable, overly difficult goals do not contribute to improved performance. According to Locke, it is necessary to derive a "moderately difficult" goal that is accepted by the subject worker. In this study, no attempt was made to solicit subjects' input in determining the "optimum" goal for this research. No check was made to verify the subjects' acceptance.

The determination and selection of the goal duration used in this study is based on the experimenter's experience in the work place. Three and a half hours of machine run-time was an accepted normal level of performance by the employees. A four hour goal was arbitrarily considered too easily done to qualify as a moderately difficult goal, as was a six hour goal considered by all machine operators to be too difficult. Therefore, the goal of five hours was chosen by the experimenter and labeled "moderately difficult." This is not in strict accordance with Locke's theory and, therefore, is not a true application of his work. 
The realities of field work and constraints that such real-world study places on applications of theory also impacted the experimenter's ability to verify goal acceptance. And, in reality, management indeed assigned a task, a new work standard when they asked their employees to participate in this study. Employee acceptance was expected, not doubted. But again, no scientific check was attempted to verify whether the workers actually accepted the goal. This further contributes to the uncertainty that strict adherence to Locke's requirements were not achieved.

Different goals were given to three groups of machine operators as a prelude to a six-week productivity study. A one way analysis of variance of change scores was used to test the first hypothesis: Goals and feedback will significantly improve productivity. With the understanding that goal difficulty and acceptance have not been strictly adhered to, this hypothesis is in keeping with Locke's Goal Theory.

A Motivating Potential Score was obtained by questionnaire before and after the six-week productivity study. Student's $\underline{t}$ tests were used to compare before and after scores to test the second hypothesis: The MPS of the workers receiving goals and feedback from the work place will significantly increase and will increase significantly their productivity. This hypothesis is in keeping with the Job Characteristics Model. 
CHAPTER II

METHOD

OMARK INDUSTRIES is a manufacturing concern that produces saw chain and related products for world-wide distribution.

The Portland facility operated 24 hours a day with three work shifts in the summer of 1986. The first shift was "grave yard" and began at midnight and continued till 7:30 am when the second or day shift began. The day shift continued till 4:00 pm when the third or "swing" shift began and operated till midnight. The employees were allowed to rotate shift assignments every six weeks and often did so.

The saw chain was produced on DUO-MATIC machines. A DUO-MATIC machine comprised several small sorting and assembling devices that worked harmoniously with the aid of a microprocessor; a computer that controlled the timing, sequence, and assembly order of the 8,200 parts that comprised a 100 foot length of cutting chain. The microprocessor also kept a running total of the machine run-time and fault counts. Thirteen micro switches situated at various locations along the assembly route of the chain being formed indicated missing parts or other 
malfunctions in assembly that would otherwise produce a flawed chain. These indicators, when activated, shut down the machine and registered a fault.

Besides the assembly function of a DUO-MATIC, the machine was also equipped with a joiner or rivet spinner that was operated by the machine operator. The joiner was located at the end of the assembly process on each Duo Matic and was used to join ends of a chain to form a loop which correctly fit the user's chain saws.

There were many factors that affected an operator's output that were not under the daily direct control of the operator, that is, availability of parts, the quality of those parts, and scheduled footage for the shift. other factors included duties that the operator may have been required to perform other than actually running a machine such as auditing chain quality, packaging, preparing completed orders for shipping, moving completed orders to receiving, and cleaning the machine at the end of the shift. These factors were not addressed in this experiment. The actual time that the subjects operated the DUO-MATIC was the condition investigated in this experiment.

The six-week duration of the experiment conformed to OMARK's six-week shift change schedule. Vacations took place during the six-week experiment. Vacation schedules of the subjects could confound the subject's 
continuous performances over the experimental period. An alternate subject, trained in the feedback and goal setting conditions with regular experimental subjects, filled in for vacationing subjects. The department selection would have been confounded by the experimenter's participation as a subject since he was a working employee of OMARK, operating a Duo Matic during the six-week experiment. To eliminate the potential for experimental contamination and bias, the experimenter's chain department was eliminated from the experiment. That left three chain departments to be randomly assigned to conditions.

\section{Subjects}

The 18 subjects that normally run the selected experimental machines, nine per shift, operated the machines throughout the six-week period.

An alternate subject was randomly selected to operate an experimental machine in the event of a subject's vacation or sick day. No replacements were necessary.

In the event that a machine chosen for the experiment had no established operator, one was chosen in the usual manner of assignment, and he or she worked as a machine operator throughout the six-week experiment. 
Machines

After eliminating the chain department in which the experimenter worked, three chain departments remained. Each chain department had at least seven and as many as 12 machines. Three machines were randomly selected from each of the remaining three chain departments. Nine DUO-MATIC chain machines, three from each department, were randomly assigned to an experimental condition: feedback followed by daily goals, feedback followed by hourly goals, and a no treatment, "do your best" control.

\section{Shifts}

The experiment was replicated on a second shift. Ideally, the two shifts would have been randomly assigned from the three available: day, swing, and graveyard shifts. The three shifts contributed disproportionately to the daily total chain produced. The day shift was the most productive because it was the best staffed and the machines were run most consistently. As customers' orders for chain were completed, machines were progressively shut down through the day and night shifts, sometimes leaving a few running machines on graveyard. For this reason, to capture the most activity, the day shift and the swing shift were selected as the two test shifts. 
The test condition assigned to each chain department's machines remained the same for both shifts. The third or graveyard shift operated in a normal fashion. The three graveyard operators, though not included in the experiment, recorded their run time and fault count on the regular company forms.

\section{Survey Instrument}

At the beginning of the experimental period, the work motivation and the present job satisfaction of 18 participating operators was assessed by the use of the paper and pencil MPS survey instrument. Eighteen other operators, nine from day shift and nine from swing shift, were chosen randomly to participate in the same assessment. The survey was conducted by the supervisors of the chain departments. The completed forms were identified by the employee's number in order to compare before and after scores and test condition. In total, there were 18 randomly chosen control subjects who had nothing to do with the experiment and 18 who were assigned to experimental conditions.

Hackman \& Oldham's Job Diagnostic Survey was used to assess the construct of work motivation and employee job satisfaction. The survey's statements were altered to reflect OMARK's systems and terminology. Responses to these statements (see Appendix A) collectively have been 
shown to produce a measure of intrinsic motivation: the extent to which an employee is motivated to perform because of subjective rewards or feelings he or she expects as a result of performing well. The 36 subjects were again asked to complete the survey at the conclusion of the experiment.

\section{Procedure}

Experimental Conditions. All experimental changes in normal OMARK procedure were made by the appropriate department supervisor with as little disturbance to daily routine as possible. A waiver was sought from the Human subjects Review Board for the necessity of signed permission slips by the subjects acknowledging personal participation in the experiment. This waiver was granted on the grounds that this thesis utilized institutional data and OMARK would not permit their employees to be approached. OMARK agreed to be responsible for their employees' participation. (See Appendices B and C)

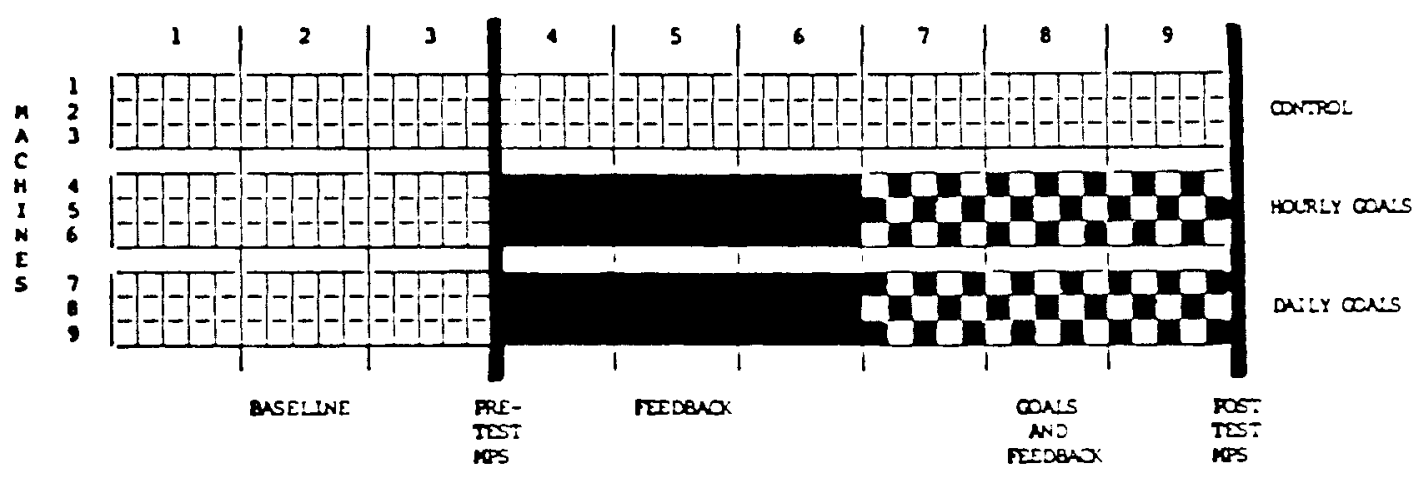

Figure 2. Diagram of the Three Conditions and Chronological Sequence of Events. 
Control condition. The three machines in the department chosen to be the control were operated in a normal fashion with the following exceptions. A time piece was affixed to the joiner at eye level. Each machine operator read temperature and humidity readings each hour on the half hour and recorded the findings on the supplied form (see Appendix D). The operator took fault count readings on the hour and recorded them on the same form. The machine run-time was recorded at the end of the shift. This reporting was normal procedure and used the existing company forms. As far as the operators were aware, the above duties represented the extent of the experiment for their department. They continued to take the readings for the six-week duration of the study.

Feedback--Hourly Goal condition. The six remaining machines participated in the feedback phase of the experiment for three weeks. Feedback was accomplished by reading and recording the elapsed run-time from the micro-processor every half-hour on a form supplied by me. An inexpensive digital time piece was affixed to the joiner at eye level to aid the operator's accurate readings. The time piece also served as a reminder to be diligent. After three weeks of feedback, the operators of three machines received hourly goals. Three operators began to compare the feedback from the micro-processor to a constant goal established for each hour period. 
The goal for each hour was 0.7 hours $(42$ minutes per 60 minute period) for each operator/machine. At each recording, the operator indicated on a form provided by me (see Appendix E): 1) the attainment of the goal $(\sqrt{ }), 2$ ) a run-time gain in excess of the goal expressed as $a+1,+2$, etc., which represents tenths of machine run hours, or 3 ) a run-time loss expressed as $-1,-2$, etc. For simplicity the goal was expressed in whole numbers on the provided form. No arithmetic was necessary. The operator simply compared the figure that appeared on the form for a particular hour period to the run-time shown on the microprocessor.

Feedback--Daily Goal condition. The remaining three machines, after participation in three weeks of feedback, entered a three week goal condition expressed in daily shift terms. Each operator was asked by management to produce five hours (i.e., 5.0) run time during their shift. That was their goal. They were still receiving feedback on the run time of their machine. The total run-time for the shift was recorded on the company forms. At the end of the shift, the operator delivered the goal forms to the supervisor's work station. It should be noted that the goal was the same for both goal conditions--five hours of run-time. 


\section{RESULTS}

Student's $\underline{t}$ tests were performed on the means of the daily reported run times from the first phase of the three conditions to verify that they were from the same population: control vs. hourly $d f=10, \underline{t}=.30, \underline{p}<.50$, control vs. daily $d f=5, \underline{t}=.277, \underline{p}<.50$.

Table I reports run-time means and standard deviations by condition (See Table I) .

TABLE I

THE DIFFERENCE IN RUN-TIME MEANS BEFORE AND AFTER TREATMENT, AND THE STANDARD DEVIATION BY CONDITION
subject\#
Before
After
Difference

\begin{tabular}{cccc}
\hline 7 & 3.68 & 4.70 & 1.02 \\
8 & 3.19 & 3.92 & .73 \\
9 & 3.16 & 3.19 & .03 \\
10 & 3.11 & 3.41 & .30 \\
11 & 5.18 & 5.16 & -.02 \\
12 & 3.89 & 3.99 & .10 \\
\hline $\begin{array}{l}\text { Hourly Goal Mean } \\
\text { Standard }\end{array}$ & 3.68 & 4.10 & .42 \\
Deviation & & & .40 \\
$============================================$ \\
.79
\end{tabular}


TABLE I

(Continued)

\section{Subject\# Before After Difference}

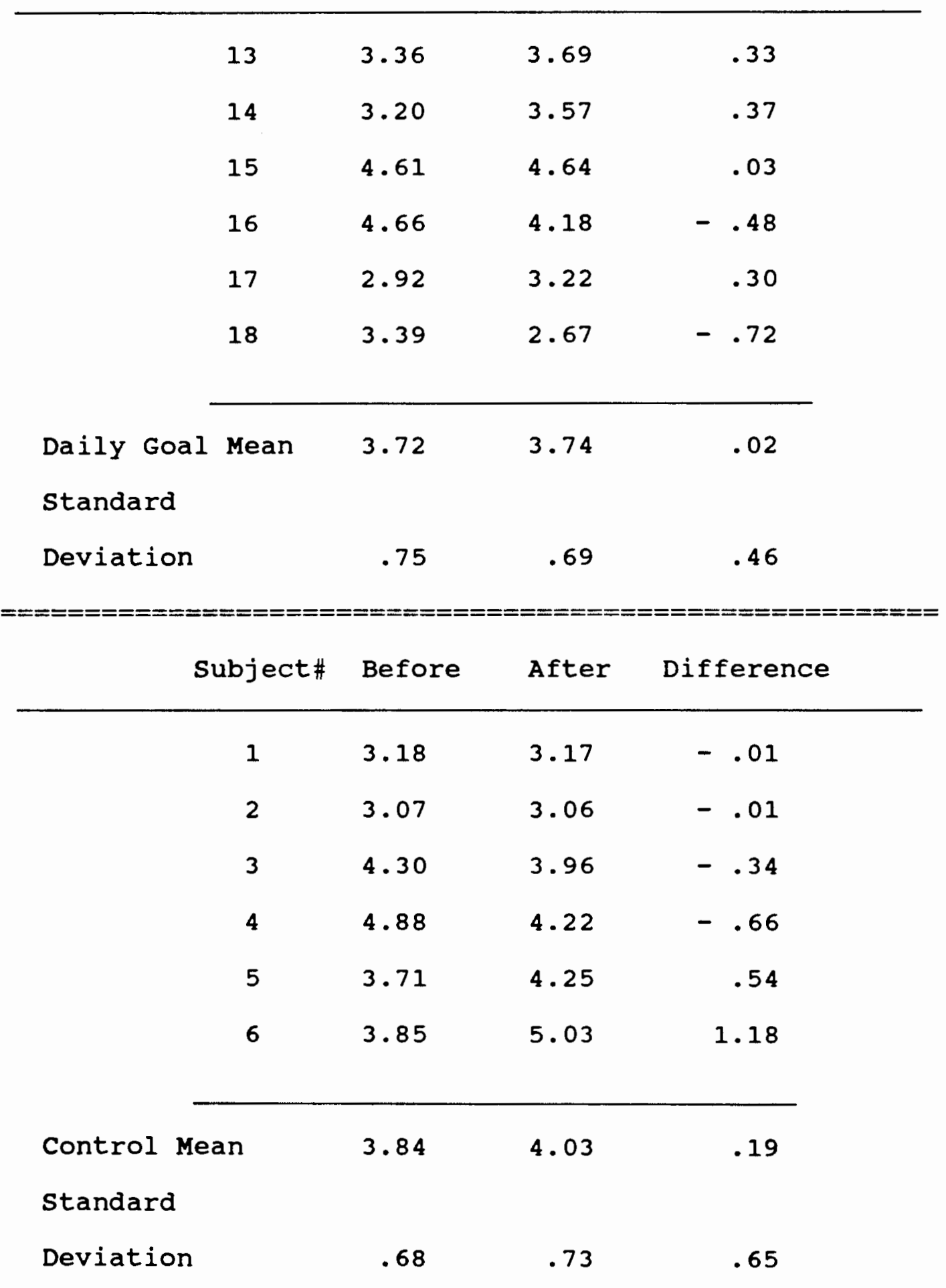


A one way analysis of variance was performed using differences in run time for the two experimental and the one control group (See Table II). Data recorded as (0), no run time for the shift, was dropped and 0 production days were not averaged.

TABLE II

A ONE WAY ANALYSIS OF VARIANCE USING CHANGE SCORES ON RUN-TIME

$\begin{array}{llllll}\text { Source } & \underline{S S} & \underline{\mathrm{d} f} & \underline{\mathrm{MS}} & \underline{F} & \mathbf{p}\end{array}$

$\begin{array}{cccccc}\text { Between groups } & .6284 & 2 & .314 & 1.16 & .20 \\ \text { Within groups } & 4.046 & 15 & .2697 & & \\ \text { Total } & 4.6744 & 17 & & \end{array}$

Students $\underline{t}$ tests were performed on the change in Motivating Potential Score by condition: (Control Condition $\underline{t}=.805 \underline{p}<.50$ ) (Hourly Condition $\underline{t}=.985$ p $<.50$.

Changes in the autonomy sub-scale and feedback subscale for those subjects in feedback and goals conditions were compared using student's $\underline{t}$. The increase reported in perceived autonomy was significant $d f=15, \underline{t}=2.539, \underline{p}$ $<.05$. No significant change was noted in feedback subscale $d f=15, \underline{t}=.328, \underline{p}>.50$.

Table III reports change in MPS and change in production by subject (See Table III). 
TABLE III

CHANGE IN MOTIVATING POTENTIAL SCORE AND CHANGE IN PRODUCTION BY SUBJECT

\begin{tabular}{|c|c|c|c|c|c|c|c|c|}
\hline S\# & MPS & Prod. & $S \#$ & MPS & Prod. & S\# & MPS & Prod. \\
\hline 1 & 68 & -.01 & 7 & 47 & .33 & 13 & -41 & 1.02 \\
\hline 2 & -50 & -.01 & 8 & -10 & .37 & 14 & 11 & .73 \\
\hline 3 & -2 & -.34 & 9 & 46 & .03 & 15 & 4 & .03 \\
\hline 4 & $x^{a}$ & -.66 & 10 & 24 & -.48 & 16 & 2 & .30 \\
\hline 5 & 85 & .54 & 11 & 9 & .30 & 17 & -30 & -.02 \\
\hline 6 & $x^{a}$ & 1.18 & 12 & -83 & -.72 & 18 & -2 & .46 \\
\hline
\end{tabular}

A correlation was obtained relating change in MPS and change in production for the 18 experimental subjects $(\underline{r}=.17)$. The correlation between Run-time and MPS in the hourly goal condition was found to be stronger $(\underline{r}=.58)$ for these 6 subjects. These correlations were not significant.

student's $t$ tests were performed on the change in MPS of the eighteen subjects involved actively in this study and the scores of the eighteen other machine operators whose only participation was limited to participation in the pre and post Job Characteristics Survey $(\underline{t}=3.32 \underline{p}<.01)$. A comparison of scores is given in Table IV. 
TABLE IV

MOTIVATING POTENTIAL SCORE CHANGE

FROM PRE TO POST TESTING

EXPERIMENTAL SAMPLE

subject\# MPS

168

$2-50$

$3-2$

$4 \quad X X$

$5 \quad 85$

$6 \quad \mathrm{XX}$

$7 \quad 47$

$8-10$

946

$10 \quad 24$

119

$12-83$

$13-41$

$14 \quad 11$

154

$16 \quad 2$

$17-30$

$18 \quad-2$

Total $^{a}$
FACTORY SAMPLE

subject\# MPS

19

$-38$

20

$-176$

21

37

22

$-192$

23

57

24

$-45$

25

30

26

$-174$

27

$-131$

28

$-55$

29

$-15$

30

$-268$

31

$-27$

32

$-30$

33

$-37$

34

$-38$

35

$-100$

36 $-33$

$-1235$

$a_{A}$ negative value for Total indicates a decrease in MPS from pre to post testing. 


\section{CHAPTER IV}

\section{DISCUSSION}

The results showed no statistically significant increase in the worker's productivity under any of the conditions. The Motivating Potential Score of the workers involved in the three experimental conditions increased between pre and post testing, but the change was not statistically significant. There was no significant change in the workers' perception of feedback, a sub-scale of the MPS. Since there was no increase in productivity, the first hypothesis, "Goals and feedback will significantly improve productivity," was not supported. Likewise, the second hypothesis, "The MPS of the workers receiving goals and feedback from the work place will significantly increase and the workers will increase significantly their productivity," was not supported because there was not a statistically significant increase in productivity, though there was a small increase in MPS for the experimentally affected workers.

The increase in production, while not statistically significant, was predicted by both Locke's Goal Theory and Hackman and Oldham's Job Characteristics 
Model. The results of this study do not support either theory. Locke's Goal Theory predicted an increase in production by the introduction of goals with knowledge of results. The Job Characteristics Model would predict the same but with a measurable accompanying increase in Motivating Potential Score, primarily, in this study, an increase in feedback from the environment. No statistically significant increase in overall MPS was obtained, but the experimental groups' MPS scores did resist the statistically significant decrease in MPS reported by the 18 subjects representing the uninvolved machine operators.

The control group showed the least increase over baseline in production. The Hourly Goal condition with feedback reported the largest increase. Because the increase was not statistically significant, speculation is not warranted. It is noteworthy to mention, though, that the condition with the stated hourly goals with feedback produced the largest increase.

After the study was over, the supervisor of the chain department that served as control for the experiment made the comment, "Gee, this stuff is great. It's a lot like what we've been doing." With questioning I discovered that the supervisor had been providing all his workers with weekly production goals and daily feedback of how each shift was contributing to 
the projected goal. He thought that it had improved production so he continued to supply this information to his workers and he took pride in their leading production totals.

Again, looking at the data now knowing the control group was using and had been using a form of feedback and goals for over a year, the fact that the hourly goal condition with feedback out-performed the control group in just six weeks is encouraging.

The MPS of those workers involved with the experiment did not change as expected. Feedback was supplied to the workers and it should have directly affected the MPS in a positive direction. Production might not increase for those workers, as was the result, but if the job enrichment formula is responsive to the real world, the MPS should have increased with the addition of feedback. No change was noted.

Upon further investigation, while the MPS for those workers involved with the experiment did not increase, the eighteen other workers who were not actively involved with this study who also took the Job Enrichment Questionnaire at the same time as the experimental subjects showed a dramatic change. While the experimental groups' MPS remained the same, the MPS for the other non-involved group of OMARK employees dropped significantly. Caution should be exercised in 
interpreting this change because little is known about the non-involved group's production or working conditions. But, since they were not involved in the experiment other than taking the questionnaire once in June and again in late July, their scores could reflect the regular factory employee's decrease in job satisfaction as the summer progressed.

Why did the MPS for the group representing the experiment's non-involved workers drop and the experimental group's MPS did not? While feedback was offered to the workers, no increase in the feedback subscale was found. It is interesting to note that the perceived autonomy of the experimental group did significantly increase. It is suggested here that the goals and feedback of this latter group served to increase the workers' autonomy, which did affect their perceptions of enrichment and perhaps helped to off-set the recorded factory decrease.

The sample size in each experimental condition of this study was small and did not provide statistically significant results. The design would be greatly improved by a larger number of subjects per condition. But in a field study, there are constraints that must be considered. There is a limited number of operators and limited pairs of operators and machines from which to choose. Another factor originally not known about the 
population is of interest. Originally the people hired to run machines were chosen for a desirable personality characteristic demonstrated in a psychological test. The most important characteristic sought in potential machine operators in the past was a "sedentary personality." A sedentary personality will be satisfied with what others might think of as boring. They will be content to sit and operate a machine day after day and not get frustrated and leave. At least this was the theory used many years ago at OMARK according to a shift supervisor. Unfortunately, this type of personality strongly resisted change and the selection process was discontinued. But most of those who were originally hired, true to the theory, have not left!

The chosen population under study needs some consideration for its particular strengths and weaknesses. Instruction and training time should be tailored to the known abilities of the work force. In this study, I believe the three-week practice time was adequate. But, if more time was given for practice, perhaps the subject workers would have had fewer objections to the change, having had more time to adjust.

The supervisors were trained in procedure and given scripts to introduce the experiment to their workers. The hoped for result was meaningfulness. I 
had hoped that if workers received their new direction from management, the new direction would be taken more seriously than if a peer or an outsider was asking them to change for no apparent reason. Using the chain of command to implement the design to increase meaningfulness actually may have decreased standardization. It might be better to appoint one supervisor to introduce all employees to the study, or secure management's approval and support for a third party to introduce the study. The most obvious drawback to using naive trainers instructing from a script after minimal training is their inability to answer unanticipated questions from subjects.

As a consequence of the experience derived from this study, certain design and procedural changes would seem appropriate in a future study. For example, with management's approval the largest number of subjects possible should be recruited and assigned. Perhaps management would approve total cooperation if their understanding warranted it.

The largest constraint of all though, for any field study in a Fortune 500 company, is management consent. This pilot study utilized only nine machines out of 30 possible to minimize the disruption of the work place and to gain approval from management to manipulate the work place. I hope that these results 
will encourage additional study utilizing all available machines and operators.

Management does not need statistically significant results to know they benefit from some process. With these kinds of numbers, one hour run time $=1800$ feet of chain, a $2 \%$ improvement in run-time can produce a large increase in profit. These trends are encouraging. More could be done to produce significant results in production improvement. The benefits of this research are shared by management and worker alike. The benefit of increased production with no increase in expense is obviously attractive to management. But the worker shares in the benefits, too. Improved productivity could translate into higher wages. That is an obvious benefit to workers. But more importantly, if work can be enriched at minimal or no cost as in this study, the work force potentiality could be released from work-aday toil to meaningful, even enjoyable, participation.

I believe this study was worthwhile for three reasons. To the best of my knowledge, Goal Theory has not been used on subjects operating under a restrictive ceiling for production. Subjects previously tested have not been constrained by a machine's maximum ability to produce in a given time. Until now, all research of production has been open ended in regard to how much 
could be done. The only constraint was the subject's willingness or motivation to do more.

Second, no study was found that compared the same goal expressed in two different goal statements. This study states the same goal two different ways, both in short term (hourly) and long term (daily). Although the results were not statistically significant, the short term goal with feedback showed higher increases in production over any other goal condition.

Finally, the research reports no study that compares Goal Theory against the Job Characteristics Model. Because MPS did not increase with production, I believe that Locke's Goal Theory was more relevant in this study. While the Job Characteristics Model, again, was not disproved, I found little support that the workers believed their jobs were improved or enriched due to no overall increase in the reported MPS. I believe that short term goals and feedback on performance produced what change was found. 


\section{REFERENCES}

Bassett, G. A., (1979). A study of the effects of task goal and schedule choice on worker performance. organizational Behavior and Human Performance, 24 , 202-227.

Becker, J. (1978). Joint effect of feedback and goal setting on performance: A field study of residential energy conservation. Journal of Applied Psychology. $63,428-433$.

Carroll, S. J., Jr., \& Tosi, H. L. (1970). Goal characteristics and personality factors in a management-by-objectives program. Administrative Science Quarterly, 15, 295-305.

Erez, M. (1977). Feedback: A necessary condition for the goal setting-performance relationship. Journal of Applied Psychology, 62, 624-627.

Frost, P. J., \& Mahoney, T. A. (1976). Goal setting and the task process: I. An interactive influence on individual performance. organizational Behavior and Human Performance, 17, 328-350.

Hackman, J.R., \& Lawler, E. E. (1971). Employee reactions to job characteristics. Journal of Applied Psychology Monograph, 55, 259-286.

Hackman, J. R., \& Oldham, G. R. (1975). Development of the Job Diagnostic Survey, Journal of Applied Psychology, 60, 159-170.

Hackman, J. R., \& Oldham, G. R. (1980). Work Redesign. Redding, Mass.: Addison-Wesley.

Herzberg, F., Mausner, B., \& Snyderman, B. (1959). The Motivation to Work. (2nd ed.) New York: John wiley.

Komacki, J. \& Dore-Boyce, K. (1978) . Self-recording: Its effects on individuals high and low in motivation. Behavior Therapy, 9 , 65-72. 
Latham, G. P., Baldes, J. J. (1975) The "practical significance" of Locke's theory of goal setting. Journal of Applied Psychology, 60, 122-124.

Latham, G. P., and Locke, E. A. (1975). Increasing productivity with decreasing time limits: A field replication of Parkinson's law. Journal of Applied Psychology, 60, 524-526.

Latham, G. P. \& Yukl, G. A. (1975). Assigned versus participative goal setting with educated and uneducated woods workers. Journal of Applied Psychology, 60, 299-302.

Locke, E. A. (1967). Motivational effects of knowledge of results: Knowledge or goal setting? Journal of Applied Psychology, 51, 324-329.

Locke, E. A. (1968). Toward a theory of task motivation and incentives. Organizational Behavior and Human Performance, $\underline{3}, 157-189$.

Locke, E. A. \& Bryan, J. F. (1968) Goal-setting as a determinant of the effect of knowledge of score on performance. American Journal of Psychology, 81, 398-406.

Locke, E. A., Shaw, K. N., Saari, L. M., \& Latham, G. P. (1981). Goal setting and task performance: 1969 1980. Psychological Bulletin, 90 (1), 125-152.

Matsui, T., Okada, A., \& Inoshita, O. (1983). Mechanism of feedback affecting task performance. Organizational Behavior and Human Performance, 31, $114-122$.

McClelland, D. C. Atkinson, J. W., Clark, R. A., \& Lowell, E. L. (1953) The Achievement Motive, New York: Appleton Century Crofts.

Pinder, C. C. (1984). Work Motivation Theory, Issues \& Applications. City: Scott Foresman \& Co.

Strang, H. R. ; Lawrence, E. C. \& Fowler, P. C. (1978) Effects of assigned goal level and knowledge of results on arithmetic computations: A laboratory study. Journal of Applied Psychology, 63, 446-450.

Steers, R. M. (1975). Task-goal attributes, achievement, and supervisory performance. organizational Behavior and Human Performance, 13, 392-403. 
Turner, A. N., \& Lawrence, P. R. (1965). Industrial jobs and the worker. Boston: Harvard Graduate School of Business Administration.

Yukl, G. A., \& Latham, G. P. (1978). Interrelationships among employee participation, individual differences, goal difficulty, goal acceptance, goal instrumentality, and performance. Personnel Psychology, 31, 305-323. 


\section{APPENDIX A}

\section{JOB CHARACTERISTICS SURVEY}

1. The job (operating a duo-matic) requires me to use a number of complex or high-level skills.

2. The job (building chain) requires a lot of cooperative work with other people.

3. The job (running a machine) is arranged so that $I$ do not have the chance to do an entire piece of work from beginning to end.

4. Just doing the work required by the job provides many chances for me to figure out how well I am doing. 5. The job (running a machine) is quite simple and repetitive.

6. The job (building chain) can be done adequately by a person working alone--without talking or checking with other people.

7. The supervisors and co-workers on this job almost never give me any "feedback" about how well I am doing. 8. This job is one where a lot of other people can be affected by how well the work gets done. 9. The job (running a machine) denies me any chance to use my personal initiative or judgment in carrying out the work. 
10. Supervisors often let me know how well they think I am performing the job.

11. The job provides me the chance to completely finish the pieces of work I begin.

12. The job (the duo-matic) itself provides very few clues about whether or not I am performing well. 13. The job gives me considerable opportunity for independence and freedom in how I do the work. 14. The job (machine operator) itself is not very significant or important in the broader scheme of things. 


\section{APPENDIX B}

\section{OMARK'S STATEMENT OF RESPONSIBILITY}

\section{OMARK INDUSTRIES}

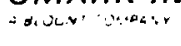

OREGON SAW CHAIN OIVISION

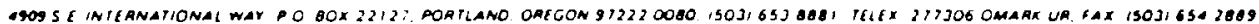

Decerber 4, 1987

To whom it May Concern,

Orark has agreed to be responsible for their employees participation in an institutional study done by Stephen Kildahl and amark Industries during the months of May, June, July and August of 1986.

Sincerely,

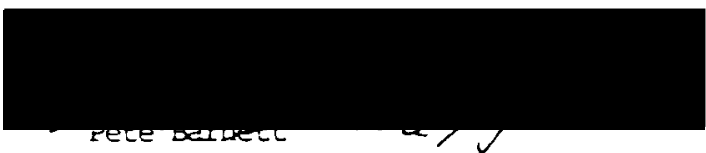

Enoloyment Marager 


\section{Portland State University}

AII:AURANDUAI

HUMAN SURJECTS RESEARCH REVIEU COMMITTEE

1987.88

DATE: 3 May 1988

IO: Stephen K1ldahl, PSY

FROH: Robert C. Holloway, Chalrperson $R$

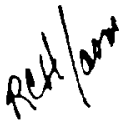

Human Subjecta Research Reviev Compltee (HSRRC)

RE: HSRRC Approval

In eccordance wth your request, the Hum Subjects Research Reviev

Combltee has revieved your proposal entitled Hork Kotlvation Analys 15 for compliance vith DHHS policles and regulations on the protection of human subjecta.

The comittee is satisfled that your provisions for protecting the rights and velfare of all subjects particlpating in the research are adequate and therefore the project is approved. Any conditions relative to this approval are noted below:

no further conditions

c: Offlce of Grants and Contracts

RCH : asm 


\section{APPENDIX D}

MACHINE RUN-TIME RECORDING FORM

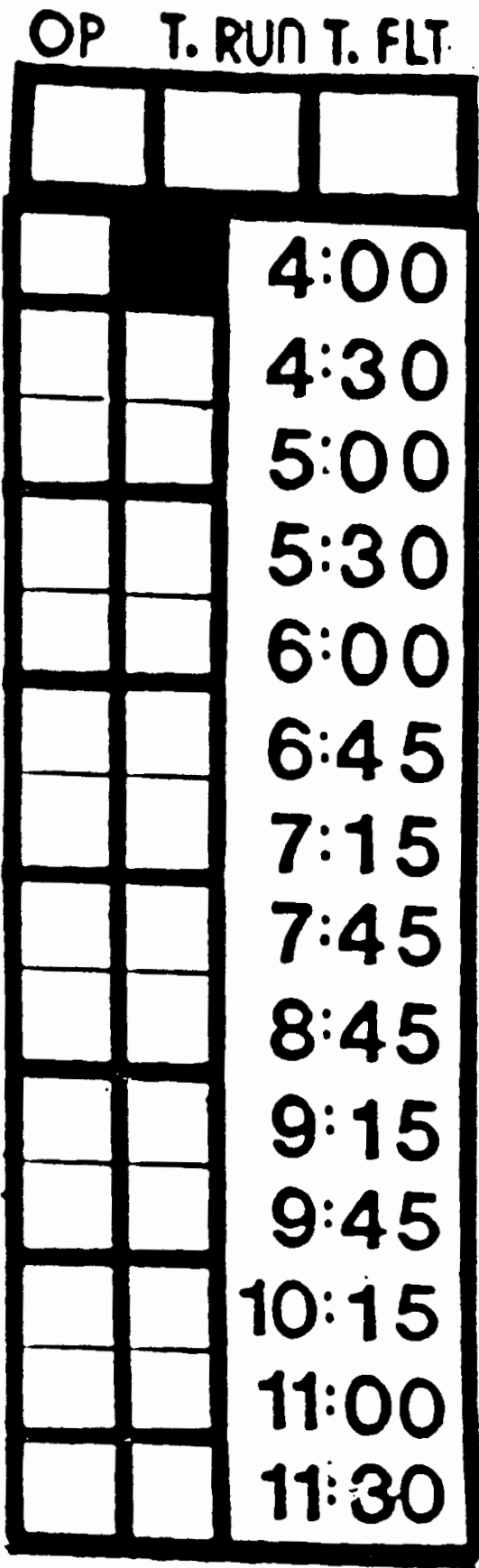


MACHINE RUN-TIME RECORDING FORM USED IN HOURLY GOAL CONDITION

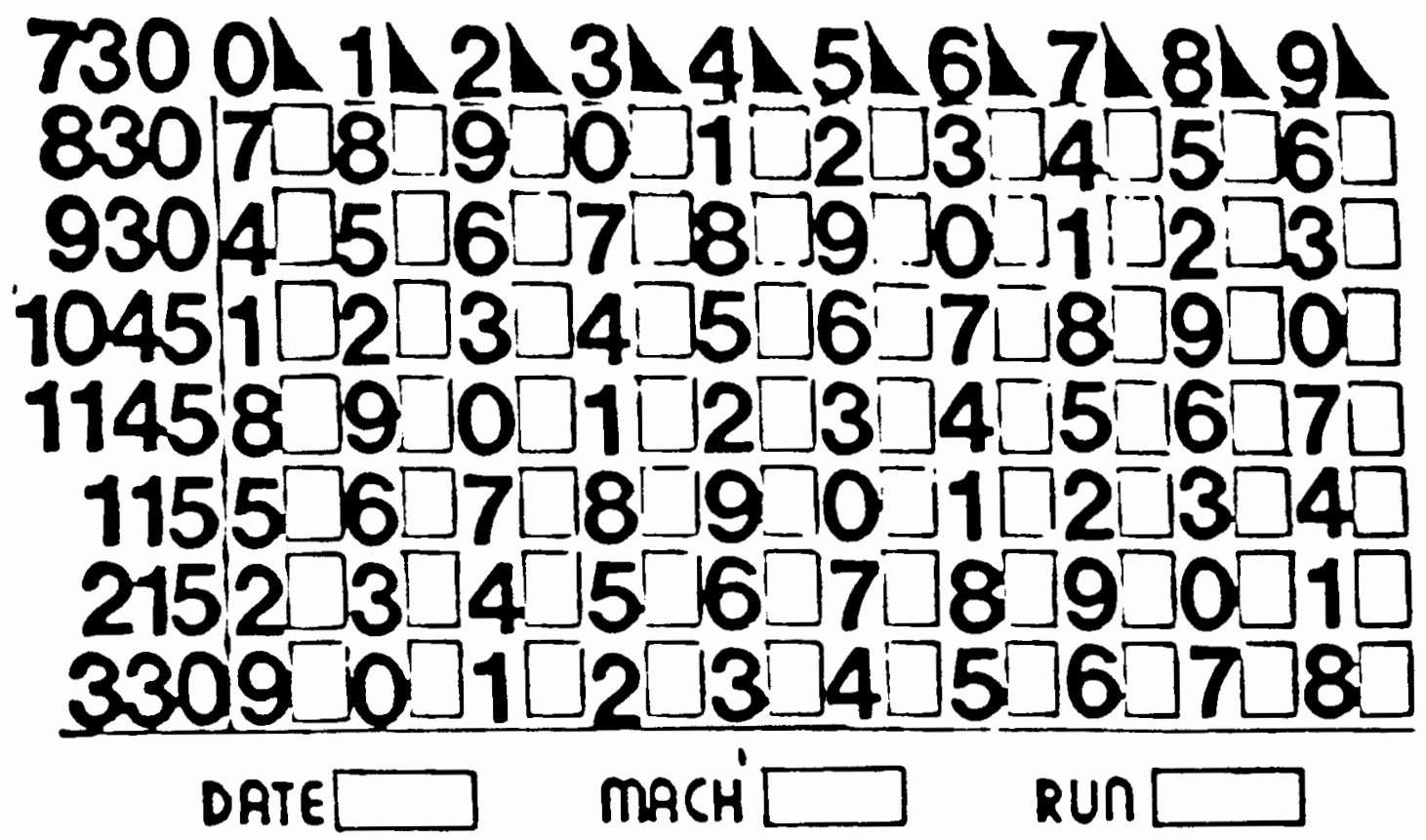

